Article

\title{
Improving the Sustainability Effectiveness of Traditional Arts and Crafts Using Supply-Demand and Ordered Logistic Regression Techniques in Taiyuan, China
}

\author{
Bo Zhu ${ }^{1}$ (D), Si-Qi Tian ${ }^{1}$ and Chien-Chih Wang ${ }^{2, *(D)}$ \\ 1 School of Statistics, Shanxi University of Finance and Economics, Taiyuan 030006, China; \\ zhubo1981@sina.cn (B.Z.); siqi_tian@yeah.net (S.-Q.T.) \\ 2 Department of Industrial Engineering and Management, Ming Chi University of Technology, \\ New Taipei City 243303, Taiwan \\ * Correspondence: ieccwang@mail.mcut.edu.tw; Tel.: +886-2-2908-9889
}

check for updates

Citation: Zhu, B.; Tian, S.-Q.; Wang, C.-C. Improving the Sustainability Effectiveness of Traditional Arts and Crafts Using Supply-Demand and Ordered Logistic Regression Techniques in Taiyuan, China. Sustainability 2021, 13, 11725. https:// doi.org/10.3390/su132111725

Academic Editors: Lucia Marchegiani, Enrico Cori and Fabio Carlucci

Received: 21 September 2021

Accepted: 21 October 2021

Published: 23 October 2021

Publisher's Note: MDPI stays neutral with regard to jurisdictional claims in published maps and institutional affiliations.

Copyright: (c) 2021 by the authors. Licensee MDPI, Basel, Switzerland. This article is an open access article distributed under the terms and conditions of the Creative Commons Attribution (CC BY) license (https:// creativecommons.org/licenses/by/ $4.0 /)$.

\begin{abstract}
The progression of time and shifts in the environment have brought significant changes to traditional arts and crafts of intangible cultural heritage. Consequently, enhancing and objectively assessing the sustainable value of traditional arts and crafts has assumed importance in developing tourism strategies. In China, few scholars have studied policy matching of traditional arts and crafts and intangible cultural heritage. The purpose of this paper is to propose supply-demand models and ordered logistical regression techniques to evaluate the quantitative efficacy of sustainability policies in traditional arts and crafts. The present study focuses on Taiyuan city; empirical study, analysis and results from assessing and analyzing policy measures show that building platforms, organizing exchanges, and hosting competitions and awards are fundamental strategies. The analysis of the efficacy of policy measures shows a positive correlation between price and the quality of arts and crafts products. For every $1 \%$ increase in the policy measure, the odds ratio of a sequential price increase is 1.04 times the original value, and the odds ratio of a sequential improvement in the manufacturing of arts and crafts is 1.06 times the original. The research results can be used as a reference to formulate accurate implementation of policies by the relevant departments, thereby accelerating the sustainability of traditional arts and crafts.
\end{abstract}

Keywords: intangible cultural heritage; cultural preservation; policy matching; questionnaire analysis; statistical techniques; case study

\section{Introduction}

Traditional arts and crafts embrace the traditional techniques and skills that human beings have created and transmitted, in a living and authentic form, down to the present, forming an essential part of China's intangible cultural heritage [1-4]. Traditional crafts contain cultural values, ideological wisdom, and practical experience and are essential to preserving intangible cultural heritage. In the past, traditional arts and crafts were massproduced and ubiquitous. Today, many are on the verge of extinction. The regeneration of traditional arts and crafts will help in the transmission and development of China's exceptional traditional culture. However, it will also aid the integration and development of the tourism industry and the cultural industries' value-added contribution to economic growth. Regenerating traditional arts and crafts has become essential in implementing China's cultural strength strategy $[5,6]$.

Taiyuan, the capital of Shanxi Province, is a historic city known as Jinyang in ancient times, with several important sites including Jinci Temple, Twin Pagoda Temple, and Yungang Grottoes. Figure 1 shows the location of Taiyuan, about $492 \mathrm{~km}$ from Beijing. In recent years, facing the dilemma of resource depletion, Taiyuan has been actively developing cultural tourism. Taiyuan city has rich resources in intangible culture and has 
accumulated many traditional craftsmen, boasting 16 schemes for national-level intangible cultural heritage protection and 48 schemes for provincial-level intangible cultural heritage protection. Its traditional arts and crafts feature paper cutting, figurine sculpture, clay sculpture, and brick carving, as shown in Figure 2.

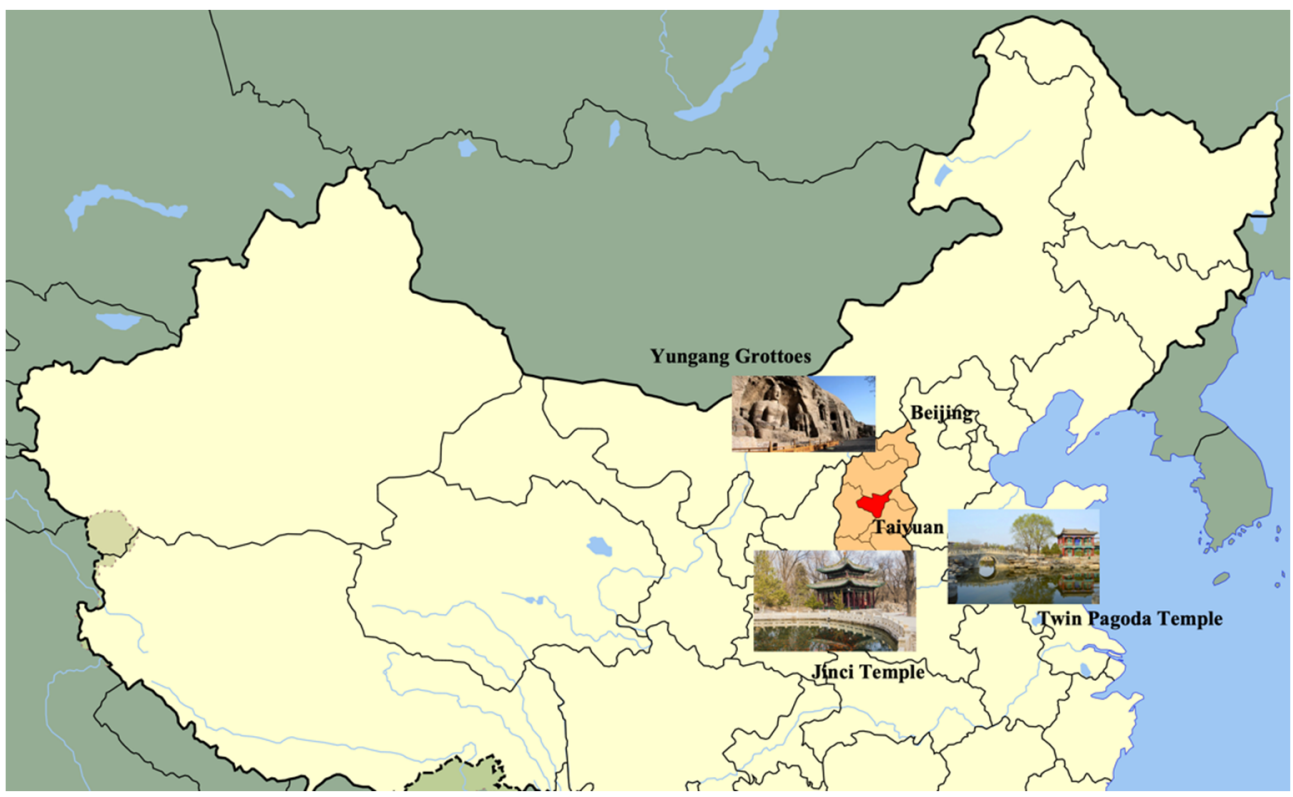

Figure 1. Location map of Taiyuan City, Shanxi Province.

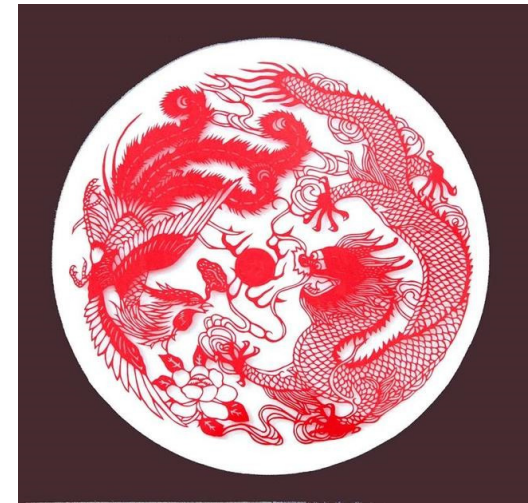

(a)

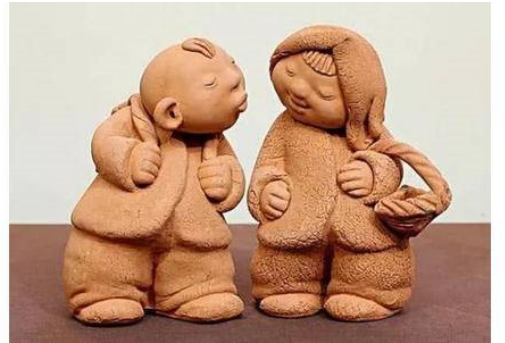

(c)

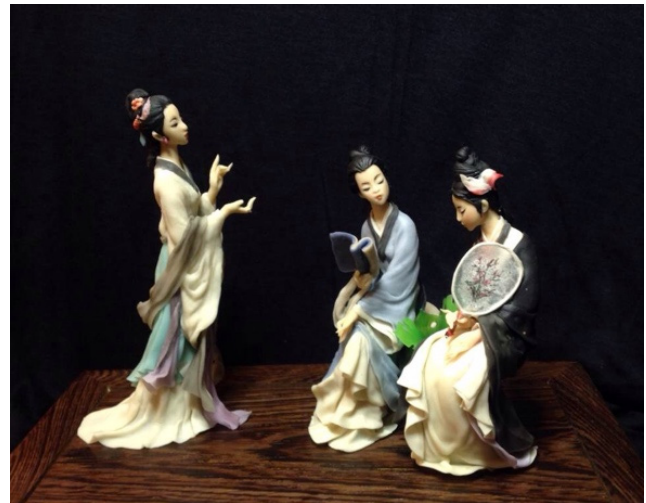

(b)

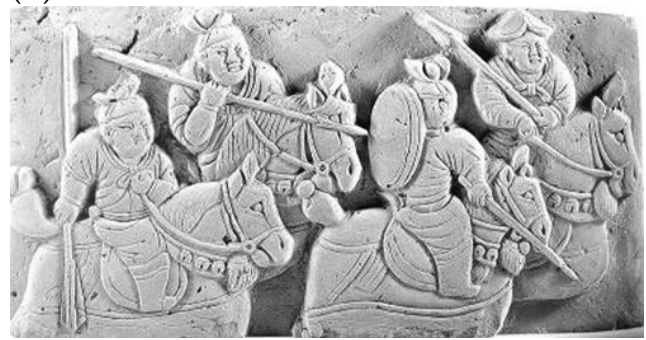

(d)

Figure 2. Taiyuan's intangible cultural heritage: (a) Paper-cutting; (b) Figurine sculpture; (c) Clay sculpture, (d) Brick carving.

Taiyuan City shows that combining intangible heritage conservation and tourism development is a "win-win" path. There is a lack of a systematic approach to assessing the sustainable value of traditional arts and crafts to determine the effectiveness of implementation strategies. In 2017, the Ministry of Culture, the Ministry of Industry and 
Communication, and the Ministry of Finance collectively published a regeneration scheme for China's traditional arts and crafts, clarifying the developmental path and 10 key tasks in the regeneration of traditional arts and crafts, thereby laying a solid foundation and environment for the regeneration and development of traditional arts and crafts [7]. Supportive measures, such as policy guidance, financial aid, platform building, and training seminars, have become important measures for the regeneration of traditional arts and crafts by local governments. In the respective supportive measures that can effectively promote the regeneration and development of traditional arts and crafts, the key is whether the policy can be effectively delivered to practitioners of traditional crafts, and whether relative measure meet the policy needs of traditional craftsmen. Therefore, it is important to develop a scientific data analysis framework to evaluate the effects of policies matching in relation to the regeneration of traditional arts and crafts.

In recent years, study on intangible cultural heritage has focused on conservation, tourism, and intellectual property. Su et al. collected 249 intangible cultural heritage papers from Web of Science focused on creative heritage tourism, community involvement in heritage conservation and development, and heritage authenticity in recent years [8]. Kin et al. explored the priorities of intangible cultural heritage practitioners in developing intangible cultural heritage as a sustainable tourism resource, using the example of Korean intangible cultural heritage practitioner empowerment and parallel development between tourism development and transmission of intangible cultural heritage [9]. Tan et al. used in-depth interviews and observations of World Heritage sites in George Town and Malacca, Malaysia, to explore the elements of 'person-place bonding' for the sustainability of heritage tourism; it was found that 'awareness' and 'creativity' are two critical codes that connect the World Heritage ecosystem [10]. Lin and Zheng produced two case studies and three sets of recommendations, particularly that intangible cultural heritage be placed under China's legislative protection as intellectual property [11]. Chinese Wushu is an essential part of intangible cultural heritage, and Liu's study points out that the proposed set of translation strategies can facilitate the better international dissemination of intangible cultural heritage [12]. From a Chinese perspective, Cheng and Yuan examine the intellectual property protection of intangible cultural heritage in China based on the current laws and regulations and then provide a semiotic approach to the relevant legal evolution in China. [13]. Dou et al. used Natural Language Processing technology to construct a knowledge base using domain ontology and instances for Chinese intangible cultural heritage and the knowledge graph [14]. Luo and Wang, according to a quantitative analysis of 12,123 items of intangible cultural heritage trademark searching data in China, found that trademark use of intangible cultural heritage symbols is in a disordered state and proposed the trademark law protection of intangible cultural heritage through awareness-raising actions, institutions, and information [15].

At present, few scholars within China have researched the issue of policy matching. There is even less academic literature on policy matching in regenerating traditional arts and crafts of intangible cultural heritage. The Taiyuan Intangible Cultural Heritage Protection Center was surveyed in August 2018 through structured interviews with representative inheritors and traditional craftsmen in the intangible cultural heritage traditional arts and crafts program. Based on 68 valid questionnaires, this paper proposed the assessment techniques for policy matching while evaluating implemented policy matching indicators and an in-depth analysis of the influence of policy matching on the regeneration and development of traditional arts and crafts.

\section{Methodology}

\subsection{Measurement of Policy Matching for Supply and Demand}

Public policy consists of measures that governments implement to resolve public issues, achieve common goals, and institute public interests [16,17]. In concrete terms, this contains law, regulations, decision-making, and action. Public policy should be effectively delivered to the target group while also meeting the values and interests of the majority 
of people in that target group. Currently, the scholarly community is placing increasing importance on research that evaluates public policy. This research is mainly centered on the effects of policy implementation, unexpected influences, as well as the cost, viability, and acceptability of policy action $[18,19]$. By comparison, policy matching has been neglected. Pencheon argues that as the challenges inherent in meeting the demands for public services grow, policy supply and demand matching should be fair and effective [20]. Xu and Han earlier pointed out that policy matching assesses the degree of satisfaction between the extent of policy support enjoyed by target groups and the actual demand for policy support. In policy implementation, there is often a large discrepancy between the impact of propaganda and policy awareness [21]. As a result, the degree of policy matching can be defined as the deliverance of a given policy to the target group and the extent to which it satisfies the target group's needs.

In this paper, we apply the policy supply and demand matching model proposed as follows.

$$
\lambda_{i j}=\cos \left(\theta_{i j}-45^{\circ}\right), \cos \left(\theta_{i j}\right)=\frac{x_{i j}^{d}}{\sqrt{\left(x_{i j}^{d}\right)^{2}+\left(x_{i j}^{s}\right)^{2}}}
$$

Here, $x_{i j}^{d}$ and $x_{i j}^{s}$ indicate the degree of demand and supply of subject $j$ toward policy measure $i ; \lambda_{i j}$ indicates the degree of policy supply and demand matching, the value of which is in the range of $[\sqrt{2} / 2,1]$. The degree of supply and demand matching for policy $i$ is $\lambda_{i}=\sum_{j} \lambda_{i j} / N_{i}$. The degree of policy support can be derived from a 5-Point Likert Scale [22]. The target groups for universal public policies should enjoy policies to an equal extent. As a result, the graded scale is not suitable for measuring the degree of universal public policy support.

In relation to this, the present study has determined three virtual variables for policy implementation, policy enjoyment, and policy demand as follows

$$
\begin{gathered}
G P_{i}= \begin{cases}1 & \text { Implemented Policy } i \\
0 & \text { Unimplemented Policy } i\end{cases} \\
C E P_{i j}= \begin{cases}1 & \text { Target } C_{j} \text { enjoying policy } i \\
0 & \text { Target } C_{j} \text { not enjoying policy } i\end{cases} \\
C D P_{i j}= \begin{cases}1 & \text { Target } j \text { with a demand for policy } i \\
0 & \text { Target } j \text { with no demand for policy } i\end{cases}
\end{gathered}
$$

There are only two values for targets $C_{j}, G P_{i} \cdot C E P_{i j} \cdot C D P_{i j}$ : Value 1 indicates policy matching and Value 0 indicates policy unmatching. The reason behind this may be that the policy in question has not been implemented, there is no demand for the policy, or there is no awareness of the policy. The aggregate degree of policy suitability is $\lambda$. The degree of matching $\lambda_{i}$ for policy $i$ and target $j^{\prime}$ 's degree of policy matching $\lambda_{j}$ is defined as follows

$$
\lambda=\frac{\sum_{i=1}^{K} \sum_{j=1}^{N} G P_{i} \times C E P_{i j} \times C D P_{i j}}{N \times K}, \lambda_{i}=\frac{\sum_{j=1}^{N} G P_{i} \times C E P_{i j} \times C D P_{i j}}{N}, \lambda_{j}=\frac{\sum_{i=1}^{K} G P_{i} \times C E P_{i j} \times C D P_{i j}}{K}
$$

The range of policy matching is $(0,1)$. By applying this policy matching equation, we can not only effectively assess the effects of policy implementation but can also discover, at a deep level, the policies and groups with a low degree of matching and assess the fairness and justice of policy action.

\subsection{Policy Matching Effect Analysis by Ordered Logistic Regression}

This study employs logical regression techniques to explore whether the degree of policy matching helps regenerate traditional arts and crafts and analyzes the corresponding 
effects. Walker and Duncan originally proposed ordinal logistic regression, an extended type of logistic regression where the categorical response variable is ordered into more than two categories $[23,24]$. Lucia et al. employed a generalized ordered logit regression to investigate residents' attitudes to tourism as a driver of regional development and the impact of digital technologies on these perceptions [25].

In this paper, we consider that no interviewees selected "decline" or "unfavorable", showing that retail prices, retail income, the standard of manufacturing, and income all have the same four assessment grades, which, as a result, can be viewed as ordinal variables. The lowest grade is set at 1 , and the highest is set at 4 . Correspondingly, the sequential development of the standard of income, retail price, retail income, and manufacturing for the interviewees from this study serve as dependent variables, which can be used to form the following ordinal logic regression model

$$
P\left(y_{i} \leq k\right)=\frac{\exp \left(\alpha_{k}-\theta \Lambda_{i}-X_{i} \beta\right)}{1+\exp \left(\alpha_{k}-\theta \Lambda_{i}-X_{i} \beta\right)}(k=1,2,3)
$$

where $y$ indicates a dependent variable, $\Lambda$ indicates the degree of policy matching, $X$ indicates the control variables, including age, gender, education, and intangible cultural heritage grade, $\alpha$ indicates cut points, and $\beta$ is the coefficient vector. As for qualitative variables, a dummy variable has been constructed around the "male" gender, using "female" as the anchoring group. For education, three dummy variables have been constructed around "high school/vocational high," "vocational college," and "undergraduate and above," with "below middle school" as the anchoring group. For intangible cultural heritage grade, two dummy variables have been constructed around "national-grade, provincial grade" and "municipal grade, county grade," with "no grade" as the anchoring group. The corresponding Odds Ratio (OR) for the degree of policy matching in the Equation (6) is

$$
\operatorname{OR}(y>k)=\frac{\operatorname{odds}\left(y>j \mid \Lambda_{i}\right)}{\operatorname{odds}\left(y>j \mid \Lambda_{l}\right)}=\exp (\theta \cdot d \Lambda)
$$

where odds $=p(y>k) / p(y \leq k)$ indicates the OR. This illustrates that for each percentile increase in the degree of policy matching, the OR of dependent variables larger than $k$ is $\exp (\theta / 100)$ times the original.

\subsection{Data Sources and Statistical Analysis}

In August 2018, Taiyuan City's protection center for intangible cultural heritage investigated the transmission and development of traditional arts and crafts in Taiyuan. Its focus was mainly on representative transmitters and traditional craftsmen in traditional arts and crafts schemes of intangible cultural heritage. Structured interviews were used to visit and survey sixty-eight traditional craftsmen, and field research was conducted to gain an in-depth understanding of the traditional craftsmen's survival environment, policy needs, and policy evaluation.

In the statistical analysis process, we used Analysis of Variance (ANOVA) to assess discrepancies in the policy matching average for different groups. ANOVA is a statistical technique to test equality among several means by comparing variance among groups relative to variance within groups [26]. York et al. used ANONA to study the effect of leisure time activities and cultural heritage awareness on students' academics [27]. In the evaluation of Ordered Logistic Regression, the Wald statistic was used for the statistical test of significance of the regression coefficient. Moreover, the test of a parallel line is applied to the model to verify further whether the influence coefficient of the explanatory variables on the OR logarithm is constant or not when the cutting points of the dependent variables take different values. To check for independence, we used Goodman-Kruskal's gamma test and Pearson's chi-squared test [28]. 


\section{Empirical Study Analysis}

In this paper, the survey employed structured interviews; the results of the descriptive statistical analysis of 68 valid questionnaires found that $61.76 \%$ were from male craftsmen, $8.82 \%$ were from national-level intangible culture transmitters, $17.65 \%$ were provinciallevel intangible culture transmitters, and $76.47 \%$ were urban craftsmen. In terms of income, $55.88 \%$ of craftsmen earned a monthly average income in 2017 that ranged between 3000 and $5000 \mathrm{RMB}, 17.65 \%$ earned between 5000 and $8000 \mathrm{RMB}$, and $11.76 \%$ earned over 8000 RMB. Based on functional characteristics, traditional arts and crafts can be divided into practical, recreational, and religious arts and crafts [8]. In this survey, $35.29 \%$ of craftsmen were engaged in practical arts and crafts, $23.53 \%$ in recreational arts and crafts, and $20.59 \%$ in religious arts and crafts. Descriptive statistics of these results are shown in Table 1.

Table 1. Descriptive Statistics Results.

\begin{tabular}{cccccc}
\hline Variable & Category & Ratio & Variable & Category & Ratio \\
\hline \multirow{2}{*}{ Gender } & Male & $61.76 \%$ & Background & Urban & $76.47 \%$ \\
& Female & $38.24 \%$ & & Pral & $23.53 \%$ \\
& Below Middle School & $14.71 \%$ & & $35.29 \%$ \\
Educational & High School/Vocational & $26.47 \%$ & Arts and Crafts & Recreational & $23.53 \%$ \\
Level & High School & Category & Religious & $20.59 \%$ \\
& Vocational College & $26.47 \%$ & & Other & $20.59 \%$ \\
& Undergraduate and above & $32.35 \%$ & & National & $8.82 \%$ \\
Below 3000 RMB & $14.71 \%$ & Intangible & Provincial & $17.65 \%$ \\
Monthly Salary & 3000-5000 RMB & $55.88 \%$ & Cultural & Municipal & $17.65 \%$ \\
& 5000-8000 RMB & $17.65 \%$ & Heritage & County & $23.53 \%$ \\
\hline
\end{tabular}

In terms of the work accomplished to promote traditional arts and crafts development in 2017, the policy enjoyment rate (i.e., the ratio of interviewees that enjoyed policy support) for platform building (including information exchange platforms, arts and crafts product development/exhibition/retail platforms, and related incubators) was $88.24 \%$. The policy demand rate (i.e., the ratio of interviewees that had a demand for a given policy) was $94.12 \%$. The policy enjoyment rate for organizational training was $29.41 \%$, while the policy demand rate was $79.41 \%$. The policy enjoyment rate for commendations and awards was $38.24 \%$, while the policy demand rate was $91.18 \%$. The policy enjoyment rate for sales channel expansion was $29.41 \%$, while the policy demand rate was $94.12 \%$. The policy enjoyment rate for industry guidance was $0 \%$, while the policy demand was $82.36 \%$. The enjoyment and demand rate for other supportive policies is shown in Table 2. Among them, the supportive policies with the most urgent demand by traditional craftsmen include financial support, platform building, sales channel expansion, governmental acquisition, tax reduction, and awards, the respective selection ratios for which are $73.53 \%, 67.65 \%$, $64.71 \%, 58.82 \%, 55.88 \%$, and $50 \%$.

Table 2. A Survey on the Policy Implementation Situation.

\begin{tabular}{ccccc}
\hline Supportive Policy & Degree of Policy & \multicolumn{2}{c}{ Degree of Policy Demand } \\
\cline { 3 - 5 } & Enjoyment & Urgent & Needed & Indifferent \\
\hline Platform Building & $88.24 \%$ & $67.65 \%$ & $26.47 \%$ & $5.88 \%$ \\
Organizational Training & $29.41 \%$ & $44.12 \%$ & $35.29 \%$ & $20.59 \%$ \\
Organizational Exchange & $38.24 \%$ & $41.18 \%$ & $47.06 \%$ & $11.76 \%$ \\
Industry Guidance & $0.00 \%$ & $44.12 \%$ & $38.24 \%$ & $17.65 \%$ \\
Holding Competitions & $23.53 \%$ & $38.24 \%$ & $35.29 \%$ & $26.47 \%$ \\
Award Schemes & $38.24 \%$ & $50.00 \%$ & $41.18 \%$ & $8.82 \%$ \\
Sales Channels Expansion & $29.41 \%$ & $64.71 \%$ & $29.41 \%$ & $5.88 \%$ \\
Financial Support & $29.41 \%$ & $73.53 \%$ & $17.65 \%$ & $8.82 \%$ \\
Government Acquisition & $11.76 \%$ & $58.82 \%$ & $17.65 \%$ & $23.53 \%$ \\
Tax Reduction & $14.71 \%$ & $55.88 \%$ & $35.29 \%$ & $8.82 \%$ \\
\hline
\end{tabular}




\subsection{Measurement and Effectiveness Analysis}

\subsubsection{Revitalization of Traditional Craft Policy Matching Measurement}

According to equation (5), we can calculate the degree of matching for each supportive policy, as well as the degree of matching for each traditional craftsman. This distribution is illustrated in Figures 3 and 4. From Figure 3, we can observe that the degree of matching for platform building is $84.85 \%$, the degree of matching for organizational exchange and awards is $36.36 \%$, the degree of matching for sales channel expansion and financial support is $30.3 \%$, the degree of matching for organizational training is $27.27 \%$, the degree of matching for hosting competitions is $21.21 \%$, and the degree of matching for tax reductions and government acquisitions is $15.15 \%$ and $12.12 \%$, respectively.

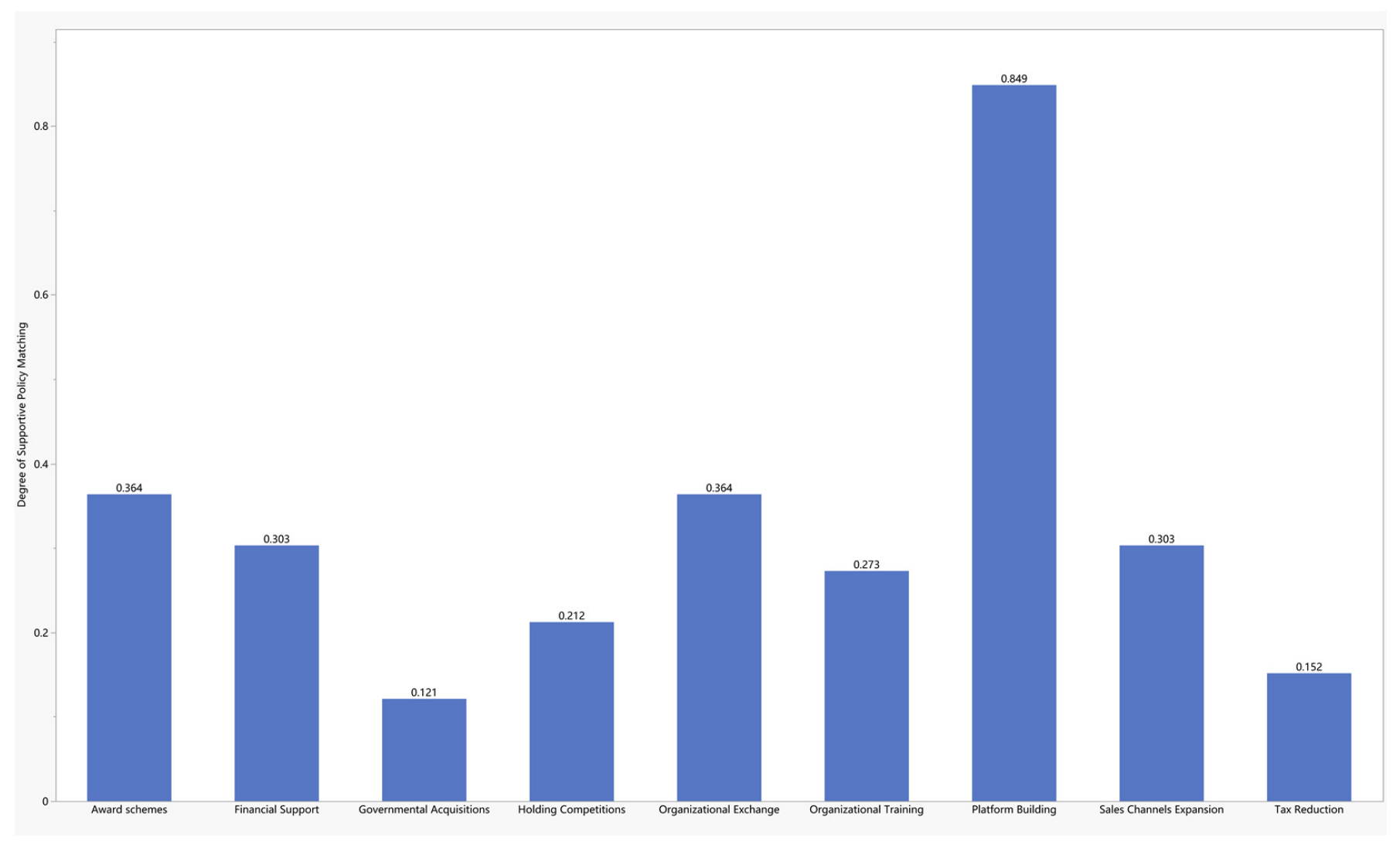

Figure 3. Distribution of the Degree of Supportive Policy Matching.

From Figure 4, we can observe that the average degree of policy matching for the craftsmen interviewed was only $28.5 \%$, with more than $53 \%$ of craftsmen enjoying a degree of policy matching below $20 \%$. This leads us to believe that greater efforts need to be made in policy implementation for regenerating the traditional arts and crafts in Taiyuan city.

From the results of Figure 5, the scatterplot of policy match and urgent need, it can be seen that practitioners of traditional arts and crafts have a highly urgent need for tax reduction, government acquisition, and financial support. However, the degree of policy matching for these measures is low. Measures to reduce tax burdens are usually aimed at companies. Since two-thirds of craftsmen create in their spare time or work from a home studio, implementing tax reductions cannot guarantee equal enjoyment of support policies among craftsmen and may disrupt market order. In addition, financial support cannot guarantee that supportive funds can be effectively applied to improve the transmission and manufacturing of traditional arts and crafts. Government acquisition can easily make traditional craftsmen focus on obtaining government resources, leading to corruption. As a result, regional governments should be cautious in their approach even 
though traditional arts and craftsmen may urgently need supportive measures, such as tax exemptions, government acquisition, and financial support.

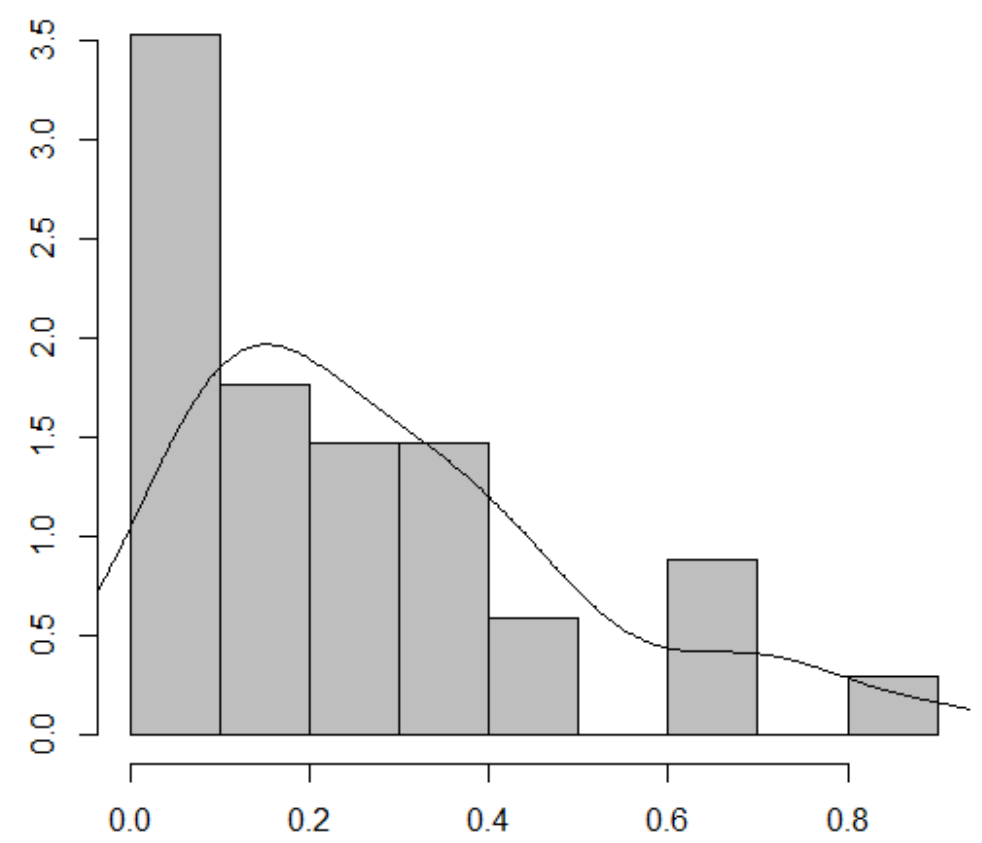

Figure 4. Distribution of the Degree of Policy Matching for Traditional Craftsmen.

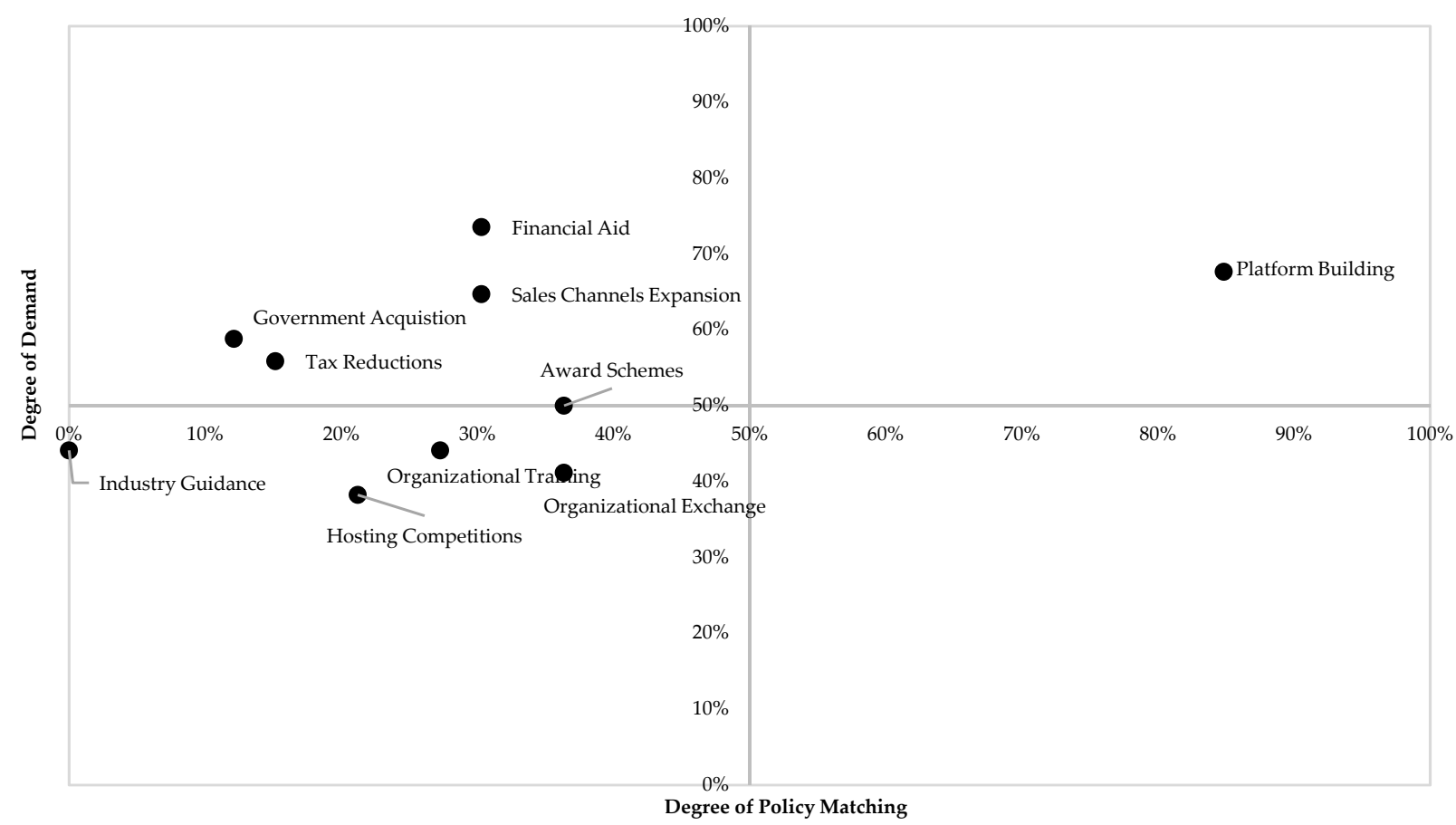

Figure 5. Distribution of the Degree of Policy Matching for Traditional Craftsmen.

The implementation of public policy should be fair and just, guaranteeing that target groups enjoy public policy measures to an equal degree. Table 3 use ANOVA assess discrepancies in the policy matching average for different groups. The results shows that traditional craftsmen with different educational records, backgrounds, and intangible cultural transmission grades as well as traditional craftsmen engaged in different forms of crafts have a corresponding F statistic of 1.236, 0.484, 0.051, and 0.526 in ANOVA, showing that there is no significant discrepancy in their policy matching mean. The policy 
matching mean for craftswomen is $37.7 \%$; for craftsmen, it is $22.9 \%$, with a corresponding F statistic of 3.966 in ANOVA, showing a fairly significant discrepancy between the two means. In addition, Spearman's rank correlation coefficient [29] for the degree of policy matching and age is 0.082 , proving insignificant; we can see that there is no significant relationship between the degree of policy matching and age. From this, we may observe that in implementing supportive measures for the regeneration of Taiyuan's traditional arts and crafts, there may be a "bias" toward females, but in general, it is fair and equal.

Table 3. A Comparison of the Policy Matching Means for Different Groups.

\begin{tabular}{cccccc}
\hline & Gender & Education & $\begin{array}{c}\text { Intangible Cultural } \\
\text { Heritage Grade }\end{array}$ & Background & Crafts Category \\
\hline Between-group mean square & 0.177 & 0.059 & 0.003 & 0.024 & 0.027 \\
Within-group mean square & 0.045 & 0.048 & 0.052 & 0.049 & 0.051 \\
F Statistic & $3.966^{* *}$ & 1.236 & 0.051 & 0.484 & 0.526 \\
\hline
\end{tabular}

\subsubsection{Analysis of the Effect of Revitalizing Traditional Craft Policy Matching}

Table 4 represents a survey of the state of Taiyuan city's traditional arts and crafts transmission and development in 2018, with an analysis of the standard of income for traditional craftsmen in 2017, the price of arts and crafts products, the income from the sale of arts and crafts products, and the crafts manufactured as relative to the sequential change in 2016. Table 4 illustrates that the sale price for arts and crafts products rose for $17.65 \%$ of the interviewees, rose slightly for $23.52 \%$, and remained the same for $41.48 \%$. Income from the same arts and crafts products rose for $12.12 \%$ of the interviewees, rose slightly for $21.21 \%$, and remained the same for $48.48 \%$. Improvements were made to the manufacturing of arts and crafts products for $35.29 \%$ of interviewees, improved slightly for $17.65 \%$, and remained the same for $41.18 \%$.

Table 4. Year on Year Change in Crafts Manufacturing and Sales for 2017.

\begin{tabular}{|c|c|c|c|c|c|c|}
\hline Assessed Aspect & $\begin{array}{c}\text { Raised } \\
\text { /Improved }\end{array}$ & $\begin{array}{c}\text { Slightly } \\
\text { Raised } \\
\text { /Improved }\end{array}$ & $\begin{array}{c}\text { Same } \\
\text { /No Change }\end{array}$ & $\begin{array}{l}\text { Slight Decline } \\
\text { /Unfavorable }\end{array}$ & $\begin{array}{c}\text { Decline } \\
\text { /Unfavorable }\end{array}$ & Not Sure \\
\hline Retail Price & $17.65 \%$ & $23.53 \%$ & $41.18 \%$ & $11.76 \%$ & $0.00 \%$ & $5.88 \%$ \\
\hline Retail Income & $12.12 \%$ & $21.21 \%$ & $48.48 \%$ & $9.09 \%$ & $0.00 \%$ & $9.09 \%$ \\
\hline Manufacturing & $35.29 \%$ & $17.65 \%$ & $41.18 \%$ & $5.88 \%$ & $0.00 \%$ & $0.00 \%$ \\
\hline
\end{tabular}

Because Equation (6) is a non-linear regression model, its parameter estimation can be derived from a maximum likelihood estimate. Table 5 shows the results of using $R$ language to estimate Equation (6). From the model fitting information, we may observe that the chi-square statistics of the regression model corresponding to the standard of income and retail income are 7.064 and 5.724, respectively, which does not pass the significance test. The Wald statistic [30] for the degree of policy matching in the two regression models for both price and manufacturing prove to be statistically significant, showing that the degree of policy matching has a significant influence on raising the price of arts and crafts products and improving manufacturing.

A test of parallel lines must be applied to the model to verify further whether the influence coefficient of the explanatory variables on the OR logarithm is constant or not when the cutting points of the dependent variables take different values. As proposed by Brant's Wald test [31], the results of conducting a parallel line test are illustrated in Table 6 . The corresponding logical regression chi-square statistics of prices and manufacturing are 3.576 and 9.399, respectively, which is statistically insignificant, showing that no matter where the cutting point of the dependent variable is, the coefficient of the explanatory 
variables in the model always remains the same and furnishes a fundamentally reasonable ordinal logit regression model.

Table 5. Ordered Logistic Regression Estimate Results.

\begin{tabular}{|c|c|c|c|c|}
\hline & $\begin{array}{l}\text { Income } \\
\text { Standard }\end{array}$ & $\begin{array}{l}\text { Work } \\
\text { Price }\end{array}$ & $\begin{array}{l}\text { Retail } \\
\text { Income }\end{array}$ & Manufacturing \\
\hline Cut1 & $\begin{array}{l}-2.994 \\
(2.152)\end{array}$ & $\begin{array}{l}-3.406 \\
(2.180)\end{array}$ & $\begin{array}{l}-1.907 \\
(2.150)\end{array}$ & $\begin{array}{l}-3.832 \\
(2.284)\end{array}$ \\
\hline Cut2 & $\begin{array}{l}-0.173 \\
(2.091)\end{array}$ & $\begin{array}{l}-1.009 \\
(2.103)\end{array}$ & $\begin{array}{c}0.921 \\
(2.125)\end{array}$ & $\begin{array}{l}-0.417 \\
(2.175)\end{array}$ \\
\hline Cut3 & $\begin{array}{l}1.205 \\
(2.103)\end{array}$ & $\begin{array}{c}0.715 \\
(2.104)\end{array}$ & $\begin{array}{c}2.408 \\
(2.172)\end{array}$ & $\begin{array}{c}0.327 \\
(2.167)\end{array}$ \\
\hline Policy Suitability & $\begin{array}{c}0.635 \\
(1.828)\end{array}$ & $\begin{array}{l}3.685^{* *} \\
(2.013)\end{array}$ & $\begin{array}{c}1.118 \\
(1.853)\end{array}$ & $\begin{array}{l}5.964^{* *} \\
(2.430)\end{array}$ \\
\hline Age & $\begin{array}{l}-0.031 \\
(0.031)\end{array}$ & $\begin{array}{l}-0.018 \\
(0.031)\end{array}$ & $\begin{array}{c}0.016 \\
(0.031)\end{array}$ & $\begin{array}{l}-0.047 \\
(0.033)\end{array}$ \\
\hline Gender $($ Male = 1) & $\begin{array}{l}-1.095 \\
(0.910)\end{array}$ & $\begin{array}{l}-1.219 \\
(0.921)\end{array}$ & $\begin{array}{l}-1.401 \\
(0.942)\end{array}$ & $\begin{array}{l}1.707 \\
(1.054)\end{array}$ \\
\hline $\begin{array}{c}\text { Education }(\text { High } \\
\text { School } / \text { Vocational High }=1)\end{array}$ & $\begin{array}{c}0.547 \\
(1.342)\end{array}$ & $\begin{array}{c}0.569 \\
(1.400)\end{array}$ & $\begin{array}{l}-0.275 \\
(1.392)\end{array}$ & $\begin{array}{l}-1.372 \\
(1.465)\end{array}$ \\
\hline Education (Vocational College = 1) & $\begin{array}{c}0.377 \\
(1.379)\end{array}$ & $\begin{array}{c}0.534 \\
(1.350)\end{array}$ & $\begin{array}{c}1.033 \\
(1.395)\end{array}$ & $\begin{array}{l}-1.641 \\
(1.450)\end{array}$ \\
\hline $\begin{array}{l}\text { Education (Undergraduate and } \\
\text { Above }=1 \text { ) }\end{array}$ & $\begin{array}{c}0.705 \\
(1.235)\end{array}$ & $\begin{array}{l}-0.102 \\
(1.198)\end{array}$ & $\begin{array}{c}0.675 \\
(1.227)\end{array}$ & $\begin{array}{c}-2.239 * \\
(1.329)\end{array}$ \\
\hline Intangible Cultural Heritage Grade & 0.351 & -1.141 & -0.607 & 0.527 \\
\hline (Municipal, County =1) & $(0.888)$ & $(0.926)$ & $(0.890)$ & $(0.950)$ \\
\hline $\begin{array}{l}\text { Intangible Cultural Heritage Grade } \\
\text { (National, Provincial = 1) }\end{array}$ & $\begin{array}{l}1.674 * \\
(0.966)\end{array}$ & $\begin{array}{l}-0.866 \\
(0.938)\end{array}$ & $\begin{array}{l}-1.200 \\
(0.958)\end{array}$ & $\begin{array}{l}2.024 * * \\
(1.072)\end{array}$ \\
\hline & \multicolumn{4}{|c|}{ Pseudo R-Square } \\
\hline McFadden $\mathrm{R}^{2}$ & 0.094 & 0.146 & 0.080 & 0.185 \\
\hline Cox and Snell & 0.204 & 0.321 & 0.179 & 0.351 \\
\hline & \multicolumn{4}{|c|}{ Model fitting information } \\
\hline Chi-Square & 7.064 & 11.210 * & 5.724 & 13.423 * \\
\hline
\end{tabular}

Table 6. Parallel Line Test Results.

\begin{tabular}{ccc}
\hline & Chi-Square Statistic & $p$ Value \\
\hline Product Price & 3.576 & 0.999 \\
Manufactured Craft & 9.399 & 0.896 \\
\hline
\end{tabular}

There is no significant relationship between the degree of policy matching for measures supporting traditional arts and crafts and age, education, and intangible cultural heritage grade. As a result, there is no need to conduct a mediating effect test on Equation (6). The estimate results in Table 6 are of considerable interest. Moreover, Table 5 shows that under a statistical significance threshold of $5 \%$, most control variables, such as age, gender, education, and intangible cultural heritage grade, prove insignificant. This further underlines the proactive effect of policy matching on the regeneration and development of traditional arts and crafts.

\section{Discussion}

The empirical study analysis results in Table 5 show that the degree of policy matching has no significant impact in terms of raising the standard of income or retail product income for practitioners of traditional arts and crafts. In fact, a substantial number of craftsmen work in their spare time ( $41.18 \%$ of participants in this study), and their income is not 
restricted to the sales of their arts and crafts products. Other craftsmen work from a home studio (20.59\% of participants in this study). Some others run a professional studio or a commercial operation (38.24\% of participants in this study), whereby collective or company retail income differs from personal retail income.

Moreover, the degree of policy matching has a significant effect on raising the price of arts and crafts products and improving manufacturing standards. According to the ordered logistic regression estimate results, where other variables remain the same, for every percentile increase in the degree of policy matching, there is a corresponding OR value of $\exp (3.685 \times 0.01)$ for the sequential increase in the price of arts and crafts products, which is to say that the OR for the sequential increase in the price of arts and crafts products is 1.04 times the original. There is a corresponding OR value of exp $(5.964 \times 0.01)$ in the sequential improvement in the manufacturing of arts and crafts products, which is to say that the OR is 1.06 times the original. There are many government-assisted support policies for the regeneration of the traditional arts and crafts; however, this does not mean that the degree of policy matching for every supportive measure will have a similar policy effect on raising the price of arts and crafts products or improving manufacturing. In this regard, we have further created a contingency table to check for independence using Goodman-Kruskal's gamma test and Pearson's chi-squared test. The results are shown in Table 7.

Table 7. Contingency Table Independence Test.

\begin{tabular}{|c|c|c|c|c|c|c|c|c|}
\hline \multirow{3}{*}{ Supportive Measure } & \multicolumn{4}{|c|}{ Raising Retail Price } & \multicolumn{4}{|c|}{ Improving Manufacturing } \\
\hline & \multicolumn{2}{|c|}{ Pearson Chi-Square } & \multicolumn{2}{|c|}{ Gamma } & \multicolumn{2}{|c|}{$\begin{array}{c}\text { Pearson } \\
\text { Chi-Square }\end{array}$} & \multicolumn{2}{|c|}{ Gamma } \\
\hline & Value & $p$ Value & Value & $p$ Value & Value & $p$ Value & Value & $p$ Value \\
\hline Platform Building & 4.413 & 0.220 & 0.264 & 0.527 & 4.592 & 0.204 & 0.638 & $0.081 *$ \\
\hline Organizational Training & 2.857 & 0.414 & 0.375 & 0.247 & 3.357 & 0.340 & 0.313 & 0.334 \\
\hline Organizational Exchange & 5.192 & 0.158 & 0.470 & $0.075 *$ & 2.150 & 0.542 & 0.322 & 0.230 \\
\hline Holding Competitions & 11.520 & $0.009 * * *$ & 0.840 & $0.001^{* * *}$ & 5.384 & 0.146 & 0.721 & $0.018 * *$ \\
\hline Award Schemes & 5.112 & 0.164 & 0.595 & $0.016^{* *}$ & 2.514 & 0.473 & 0.323 & 0.253 \\
\hline Expansion of Sales Channels & 4.239 & 0.237 & 0.464 & $0.090^{*}$ & 2.176 & 0.537 & 0.205 & 0.518 \\
\hline Financial Support & 0.277 & 0.964 & 0.130 & 0.659 & 4.871 & 0.182 & 0.414 & 0.171 \\
\hline Governmental Acquisition & 1.034 & 0.793 & 0.000 & 1.000 & 3.380 & 0.337 & -0.244 & 0.571 \\
\hline Tax Reduction & 6.942 & 0.074 * & 0.755 & $0.039 * *$ & 0.402 & 0.940 & 0.167 & 0.656 \\
\hline
\end{tabular}

${ }^{*} p<0.10,{ }^{* *} p<0.05,{ }^{* * *} p<0.01$.

The $p$ value of raising retail prices, holding competitions, award schemes, and tax reduction are smaller than 0.05 ; the $p$-value of improvements to manufacturing and holding competitions is smaller than 0.05 . From this, we can observe that platform building (especially information-sharing platforms) and holding competitions help craftsmen exhibit their skills, exchange experience, and learn from each other's crafts, which helps improve manufacturing, often leading to rises in retail prices. Award schemes, in particular those that confer honorary titles such as "Master of Traditional Arts and Crafts," "Intangible Cultural Heritage Inheritor and Disseminator," and other related professional qualifications, will significantly raise the "brand" value and collector's value of traditional arts and crafts, further stimulating artistic innovation and tireless improvement among traditional craftsmen.

Traditional crafts are a vehicle for history and culture. Under the background of the exceptional Chinese traditional cultural heritage and dissemination program currently being built in China, many regional governments have been rushing to create policy measures to regenerate traditional crafts, on the one hand promoting their transmission and development, and on the other hand proactively coining calling cards for exceptional regional culture. The key to whether policy measures can effectively promote the transmission of traditional crafts is the extent to which policy measures are delivered to practitioners of traditional crafts and whether they meet the practitioners' policy demands. The present 
study drew on data from a 2018 survey on the state of development of the traditional crafts in Taiyuan city, calculating the degree of policy matching in supportive measures for the regeneration of the traditional crafts, further analyzing, in-depth, the influence of the degree of policy matching on the regeneration and development of traditional crafts. Our empirical results show that the degree of policy matching can accurately assess the fairness of policy implementation and the effects of policy measures. In the regeneration of traditional crafts, policy matching has a significant influence in raising the prices of traditional handcrafted products and improving manufacturing skills.

\section{Conclusions}

Following our conclusions based on empirical analysis, this study proposes three suggestions. In the first instance, we prioritize the implementation of highly effective policy measures. Supportive policies such as platform building, organizational exchange, holding competitions, award schemes, and expanding sales channels can all significantly promote price rises among the handicraft products of traditional craftsmen and improve manufacturing skills. They should therefore be prioritized for policy implementation. In carrying out platform-building policies, emphasis should be laid on multifunctional platforms that combine collective creation, exhibition, and sales, which will help craftsmen exchange traditional handicraft skills and promote the collective exhibition of traditional craftwork. In implementing organizational exchange policies, participants should be suitably organized into exchange groups differentiated by varying degrees of professionalism and technical accomplishment, thereby avoiding peer pressure that prevents participants from sharing their own experiences. In lectures, highly skilled and qualified traditional craftsmen can share their experiences and transmit their skills. In hosting competitions, the traditional crafts should be categorized to guarantee the comparability of competing projects. In implementing award schemes, we should clarify the evaluating conditions and selection procedures, promoting awards instead of subsidies, and using commendations to promote transmission, thereby thoroughly ensuring the most stimulation based on equality and fairness.

The second consideration is to launch policies with a low degree of matching but high demand. The demand for supportive policy measures such as tax exemptions, governmental acquisitions, and financial support is relatively high; however, the degree of policy matching is low. The implementation of tax exemption policies should first and foremost conform to national tax reduction policies and include traditional craftsmen within the scope of the policy. Second, when carrying out financial support policies, we should establish a unified support fund management platform and strengthen supervision of the use of funds. We should establish government acquisition standards and regulate acquisition procedures to ensure fairness, equality, and transparency within government acquisition policies. Third, we should regularly monitor the effects of the implemented policies. Strengthening the supervision of supportive policies for the regeneration of traditional crafts, viewing the degree of policy matching as a critical indicator of success, and actively assessing policy effects will guarantee that policy measures can effectively help practitioners of traditional handicrafts disseminate their skills, improving craftwork and innovative products.

This study is limited to the traditional arts and crafts of Taiyuan's intangible heritage. Future research will be based on the framework developed to research other intangible cultural heritage, traditional craft metadata standards, and statistical monitoring issues, as well as in-depth cooperation with relevant local government agencies in order to obtain more resources and expand research impact.

Author Contributions: Conceptualization, B.Z. and S.-Q.T.; methodology, B.Z.; validation, B.Z. and C.-C.W.; formal analysis, B.Z. and C.-C.W.; data curation, S.-Q.T.; writing-original draft preparation, B.Z. and C.-C.W. writing-review and editing, C.-C.W. All authors have read and agreed to the published version of the manuscript. 
Funding: This research received no external funding.

Institutional Review Board Statement: Not applicable.

Informed Consent Statement: Informed consent was obtained from all subjects involved in the study.

Data Availability Statement: Not applicable.

Conflicts of Interest: The authors declare no conflict of interest.

\section{References}

1. Howard, K. Intangible Cultural Heritage in China Today: Policy and Practice in the Early Twenty-First Century. In Music as Intangible Cultural Heritage; Routledge: London, UK, 2016; pp. 37-68.

2. Zhu, Y. Heritage and religion in China. In Handbook on Religion in China; Edward Elgar Publishing: Cheltnam, UK, 2020.

3. Zhou, Y.; Jingqiong, S.; Yujing, H. The digital preservation of intangible cultural heritage in china: A survey. Preserv. Digit. Technol. Cult. 2019, 48, 95-103. [CrossRef]

4. Jiang, L. Crafts in China. In A Cultural Economic Analysis of Craft; Palgrave Macmillan: Cham, Germany, $2019 ;$ pp. 61-73.

5. $\mathrm{Wu}, \mathrm{W}$. Cultural strategies in Shanghai: Regenerating cosmopolitanism in an era of globalization. Prog. Plan. 2004, 61, 159-180. [CrossRef]

6. Sun, M.; Chen, C. Renovation of industrial heritage sites and sustainable urban regeneration in post-industrial Shanghai. J. Urban Aff. 2021, 1-24. [CrossRef]

7. Shang, G.Y. An analysis of the integration and development initiatives of traditional handicrafts and cultural entrepreneurship in Fujian. J. Fuzhou Party Sch. 2019, 1, 32-37.

8. Su, X.; Li, X.; Kang, Y. A bibliometric analysis of research on intangible cultural heritage using CiteSpace. Sage Open 2019, 9, 2158244019840119. [CrossRef]

9. Kim, S.; Whitford, M.; Arcodia, C. Development of intangible cultural heritage as a sustainable tourism resource: The intangible cultural heritage practitioners' perspectives. J. Herit. Tour. 2019, 14, 422-435. [CrossRef]

10. Tan, S.K.; Tan, S.H.; Kok, Y.S.; Choon, S.W. Sense of place and sustainability of intangible cultural heritage-The case of George Town and Melaka. Tour. Manag. 2018, 67, 376-387. [CrossRef]

11. Lin, Q.; Zheng, L. On Protection of Intangible Cultural Heritage in China from the Intellectual Property Rights Perspective. Sustainability 2018, 10, 4369. [CrossRef]

12. Liu, X. International communication of intangible cultural heritage in central plains: A case study of Chinese Wushu. Int. J. Soc. Sci. Humanit. 2018, 2, 196-204. [CrossRef]

13. Cheng, L.; Yuchang, Y. Intellectual Property Tools in Safeguarding Intangible Cultural Heritage: A Chinese Perspective. Int. J. Semiot. Law-Rev. Int. De Sémiotique Jurid. 2021, 34, 893-906.

14. Dou, J.; Qin, J.; Jin, Z.; Li, Z. Knowledge graph based on domain ontology and natural language processing technology for Chinese intangible cultural heritage. J. Vis. Lang. Comput. 2018, 48, 19-28. [CrossRef]

15. Luo, Z.; Fang, W. From cultural symbols to commercial marks: A quantitative analysis of the trademark law protection of intangible cultural heritage in China. Queen Mary J. Intellect. Prop. 2021, 11, 158-182. [CrossRef]

16. Marume, M. Public Policy and Factors Influencing Public Policy. Int. J. Eng. Sci. Invent. 2016, 5, 6-14.

17. Ehrenberg, R.G.; Smith, R.S.; Hallock, K.F. Modern Labor Economics: Theory and Public Policy; Routledge: London, UK, 2021.

18. Howlett, M. Policy analytical capacity: The supply and demand for policy analysis in government. Policy Soc. 2015, 34, 178-182. [CrossRef]

19. Mukherjee, I.; Coban, M.K.; Bali, A.S. Policy capacities and effective policy design: A review. Policy Sci. 2021, 54, 243-268. [CrossRef] [PubMed]

20. Pencheon, D. Matching demand and supply fairly and efficiently. BMJ 1998, 316, 1665-1667. [CrossRef] [PubMed]

21. Xu, D.Y.; Han, B.T. The Model and Empirical Study on the Match between Policy Supply and Demand: Based on Innovation and Entrepreneurship Policy in Beijing. Stud. Sci. Sci. 2015, 33, 1787-1796.

22. Qiu, Q.; Zheng, T.; Xiang, Z.; Zhang, M. Visiting intangible cultural heritage tourism sites: From value cognition to attitude and intention. Sustainability 2020, 12, 132. [CrossRef]

23. Liang, J.; Guoshu, B.; Cheng, Z. Multinomial and ordinal Logistic regression analyses with multi-categorical variables using R. Ann. Transl. Med. 2020, 8, 982. [CrossRef]

24. Qi, B.; Shuyu, Q.; Aaron, C. A Predictive Analysis on Emerging Technology Utilization in Industrialized Construction in the United States and China. Algorithms 2020, 13, 180. [CrossRef]

25. De Lucia, C.; Pazienza, P.; Balena, P. How does ICT influence residents' attitudes towards tourism as a driver of development? A generalised ordered logistic regression analysis: ICT for tourism as driver of development in lagging behind regions. Int. J. Tour. Res. 2021, 1-25. [CrossRef]

26. Mair, P.; Wilcox, R. Robust statistical methods in R using the WRS2 package. Behav. Res. Methods 2020, 52, 464-488. [CrossRef]

27. ÇAĞIRKAN, B.; Bilek, G.; Telli, H. The Perception of Leisure Time and Concrete Historical and Cultural Heritage Awareness among University Students. Gümüşhane Üniversitesi Sosyal Bilimler Enstitüsü Elektronik Dergisi 2021, 12, 914-922. 
28. Metsämuuronen, J. Directional nature of Goodman-Kruskal gamma and some consequences: Identity of Goodman-Kruskal gamma and Somers delta, and their connection to Jonckheere-Terpstra test statistic. Behaviormetrika 2021, 48, 238-307. [CrossRef]

29. Kumar, A.; Abirami, S. Aspect-based opinion ranking framework for product reviews using a Spearman's rank correlation coefficient method. Inf. Sci. 2018, 460, 23-41.

30. Das, U.; Kalyan, D. Selection of influential variables in ordinal data with preponderance of zeros. Stat. Neerl. 2021, 75, 66-87. [CrossRef]

31. Brant, R. Assessing proportionality in the proportional odds model for ordinal logistic regression. Biometrics 1990, 46, 1171-1178. [CrossRef] 